\title{
The Effect of Cyclohexanol in Extraction Processes in the Production of Mineral Oils
}

\author{
Grushova E. I ${ }^{1}$, Al-Razoqi A. A $^{2}$, Alrashedi A. $\mathbf{R}^{3}$., \\ ${ }^{I}$ D.Sc (Engineering), Professor, Department of Oil and Gas Processing and Petroleum Chemistry Belarusian \\ State Technological University Republic of Belarus \\ ${ }^{2,3} \mathrm{PhD}$ student, Department of Oil and Gas Processing and Petroleum Chemistry Belarusian State \\ Technological University Republic of Belarus
}

*Corresponding Author: Al-Razoqi A. A, PhD student, Department of Oil and Gas Processing and Petroleum Chemistry, Belarusian State Technological University Republic of Belarus

\begin{abstract}
The effect of cyclohexanol on extractive processes in the composition of industrial solvents used for the purification of petroleum oil fractions was studied. It was found that cyclohexanol allows intensifying the purification of oils from unwanted components by $N$-methylpyrrolidone: the index of viscosity of raffinate is increased; the content of aromatic structures in the extract is increased.

The addition of cyclohexanol to the solvent of low-temperature crystallization allows to reduce losses of oil with slacks and to improve the quality of the raw material for the production of paraffin. The use of cyclohexanol in the extraction process does not require changes in industrial technology
\end{abstract}

Keywords: petroleum oil fraction, extraction with $N$-methylpyrrolidone, cyclohexanol, raffinate, lowtemperature crystallization, methyl ethyl ketone, toluene, modifier, base oil, slack.

\section{INTRODUCTION}

A multistage technology for processing petroleum oil fractions and tar, including the purification of distillates and deasphalted products from unwanted components (resinous asphaltene substances, polycyclic aromatic compounds with short alkyl substituents) by liquid extraction or by a combination of extraction with hydro treating, low-temperature dewaxing of raffinates in the environment of solvent, allows receiving two very important oil products. They are basic mineral oil and slack.

Mineral oils of various fractional compositions are the basis for obtaining lubricating oils for various purposes, and slack is the raw material from which soft and hard paraffins and ceresins are isolated. Paraffins are widely used in various industries: paper, textile, printing, leather, paint, food, medicine; for the production of Vaseline, wax compositions; in the chemical for the production of fatty acids and alcohols, $\alpha$-olefins, detergents, etc. Therefore, the more selectively each stage of processing of oil distillates and deasphalting takes place, the less costly is the implementation of multi-stage technology due to the reduction, primarily, of losses of target products, due to the complexity of bringing Their qualitative indicators to the appropriate level. Therefore, the development of rational methods for regulating the selectivity of separation for the stages of selective purification of petroleum oil fractions by polar solvents and the isolation of paraffinic hydrocarbons from raffinates by the method of extractive crystallization is a very important task both from a scientific and practical point of view.

Currently, $\mathrm{N}$-methylpyrrolidone is increasingly used as a selective solvent in the purification phase of petroleum oil fractions from resinous asphaltene substances, polycyclic aromatic compounds with short side chains. However, the effectiveness of this extractant decreases with heavier processed raw materials [1]. It is known [2] that it is possible to regulate the properties of the solvent in the course of liquid extraction due to the introduction of a small amount of co-extractant into it. For example, to control the selective and dissolving properties of triethylene glycol, low-molecular alcohol can be used [3]; for phenol - N-methylpyrrolidone [2]; for N-methylpyrrolidone - tetramethylene sulfone [2] and low-molecular alcohols [4]. However, if there is a significant difference in the properties of the 
components entering the solvent, for example, in the boiling point of the base extractant and the coextractant, the separation agent recovery technology becomes more complicated.

The purpose of this paper was to develop a co-extractor that, when combined with $\mathrm{N}$ methylpyrrolidone, provides improved oil distillate cleaning performance against unwanted components, and with the acetone-toluene system, an increase in the selectivity of the raffinate separation to dewaxer and slack.

Cyclohexanol was tested as co-extractant for both extraction processes.

Table 1 shows the main properties of the solvents used in the extraction processes for the production of mineral oils.

Table1. Solvents' properties

\begin{tabular}{|c|c|c|c|c|}
\hline Index & N-methylpyrrolidone & Acetone & Toluene & Cyclohexanol \\
\hline Formula & ${ }_{\mathrm{C}}^{\mathrm{l}} \mathrm{H}_{3}$ & $\begin{array}{c}\mathrm{CH}_{3}-\underset{\text { II }}{\mathrm{C}}-\mathrm{CH}_{3} \\
\mathbf{O}\end{array}$ & & \\
\hline Density at $20^{\circ} \mathrm{C}, \mathrm{g} / \mathrm{cm}^{3}$ & 1,028 & 0,792 & 0,867 & 0,962 \\
\hline $\begin{array}{c}\text { Boiling point Temperature, } \\
{ }^{\circ} \mathrm{C} \text { : }\end{array}$ & 202 & 56 & 110,6 & 161 \\
\hline Melting point & -24 & -95 & -95 & 25,4 \\
\hline Flash units & 91 & -20 & $\begin{array}{c}4 \\
\text { (closed cup) } \\
\end{array}$ & 68 \\
\hline The refractive index, $n_{\mathcal{D}}^{20}$ & 1,4700 & 1,3589 & 1,4969 & 1,4629 \\
\hline $\mathrm{TLV}, \mathrm{mg} / \mathrm{m} 3$ & 100 & 200 & $\begin{array}{c}14 \\
\left(\text { at } 14,5^{\circ} \mathrm{C}\right) \\
\end{array}$ & 10 \\
\hline $\begin{array}{l}\text { Specific heat of evaporation, } \\
\mathrm{kJ} / \mathrm{mol}\end{array}$ & 49,8 & 29 & 33,6 & 60,2 \\
\hline
\end{tabular}

\section{Selectivity Cleaning of Oil Fraction}

A study of the effect of cyclohexanol on the process of selective purification of oil distillates with Nmethylpyrrolidone was carried out on the basis of data on the extraction of vacuum distillate VD-2 $\left(393 \div 480^{\circ} \mathrm{C}\right.$ ) at $50^{\circ} \mathrm{C}$, solvent to Raw material ratio 3: 1 (m.p.). The results of the experiment are shown in Table 2.

Table2. The results of extraction of VD-2 distillate $\left(n_{\mathcal{D}}^{50}=1,5010, V_{50}=67,5\right)$ with a solvent based on $N$ methylpyrrolidone

\begin{tabular}{|c|c|c|c|c|}
\hline \multirow{2}{*}{ Solvent } & \multicolumn{2}{|c|}{ Raffinate } & Extract \\
\cline { 2 - 4 } & Yield, mass.\% & $\boldsymbol{n}_{\mathcal{D}}^{\mathbf{5 0}}$ & IV & $\boldsymbol{n}_{\mathcal{D}}^{\mathbf{5 0}}$ \\
\hline N-methylpyrrolidone & 64,5 & 1,4765 & 89 & 1,5453 \\
\hline $\begin{array}{c}\text { N-methylpyrrolidone + 1,5\% wt of } \\
\text { cyclohexanol }\end{array}$ & 66,0 & 1,4740 & 91 & 1,5470 \\
\hline N-methylpyrrolidone + 3\% wt of cyclohexanol & 65,2 & 1,4742 & 87 & 1,5445 \\
\hline
\end{tabular}

\section{DEWAXING OF RAFFINATE}

Purification of the raffinates from paraffinic hydrocarbons that increase the pour point of the oils was carried out by low temperature crystallization in a solvent consisting of a mixture of acetone-toluene (60:40) containing a cyclohexanol additive. Dewaxing of vacuum distillate VD-3 $\left(430 \div 510{ }^{\circ} \mathrm{C}\right)$ was carried out according to the known procedure [5] at a temperature of $-15{ }^{\circ} \mathrm{C}$. The results of the separation are given in Table 3 . Table 4 shows the spectral coefficients of raw materials and dewaxing products, calculated on the basis of their IR spectra [6].

Table3. Results of dewaxing of vacuum distillate VD-3

\begin{tabular}{|c|c|c|c|c|}
\hline \multirow{2}{*}{ Solvent } & \multicolumn{2}{|c|}{ Solvent Dewaxed Gach oil } & \multicolumn{2}{c|}{ gach } \\
\cline { 2 - 5 } & yield, Mac.\% & $\boldsymbol{n}_{\mathcal{D}}^{\mathbf{5 0}}$ & $\mathbf{t}_{\text {nл. }},{ }^{\circ} \mathbf{C}$ & $\boldsymbol{n}$-alkane \\
\cline { 3 - 5 } & & & 62 & 1,33 \\
\hline Acetone-toluene & 90,3 & 1,4842 & 64 & 1,38 \\
\hline (Acetone-toluene) $+0.5 \% \mathrm{wt}$ & 90,8 & 1,4855 & 62 & 1,32 \\
\hline (Acetone-toluene) $+1.5 \% \mathrm{wt}$ & 90,6 & 1,4840 & 61 & 1,33 \\
\hline (Acetone-toluene) $+2 \% \mathrm{wt}$ & 90,6 & 1,4835 & \\
\hline
\end{tabular}


Table4. Spectral coefficients of petroleum products

\begin{tabular}{|c|c|c|c|c|c|}
\hline Sample & \multicolumn{5}{|c|}{ Spectral coefficients } \\
\cline { 2 - 6 } & $\frac{\boldsymbol{D}_{\mathbf{1 6 0 0}}}{\boldsymbol{D}_{\mathbf{1 4 6 0}}}$ & $\frac{\boldsymbol{D}_{\mathbf{7 2 0}}}{\boldsymbol{D}_{\mathbf{1 6 0 0}}}$ & $\frac{\boldsymbol{D}_{\mathbf{1 3 0 0}}}{\boldsymbol{D}_{\mathbf{1 6 0 0}}}$ & $\frac{\boldsymbol{D}_{\mathbf{9 6 0}}}{\boldsymbol{D}_{\mathbf{1 4 6 0}}}$ & $\frac{\boldsymbol{D}_{\mathbf{1 0 3 0}}}{\boldsymbol{D}_{\mathbf{1 4 6 0}}}$ \\
\hline Raffinate, isolated from distillate VD-3 & 1,47 & 0,82 & 1,34 & 1,44 & 1,44 \\
\hline Dewaxer (solvent acetone-toluene) & 1,61 & 0,81 & 1,37 & 1,52 & 1,52 \\
\hline $\begin{array}{c}\text { dewaxer ((acetone-toluene + 1.5\%wt } \\
\text { cyclohexanol)) }\end{array}$ & 1,71 & 0,79 & 1,41 & 1,55 & 1,53 \\
\hline
\end{tabular}

\section{RESULT AND DISCUSSION}

According to the data in Table 2, the addition of cyclohexanol (1.5\%wt) to N-methylpyrrolidone as co-extractant allows the raffinate yield to be increased. At the same time, the quality of the purified oil improves - its viscosity index (VI) increases, and the extracted extract contains more aromatic structures, because its refractive index $n_{\mathcal{D}}^{50}$ increases. The use of cyclohexanol as a modifying additive in the dewaxing stage also has a positive effect on the process of purifying raffinate from paraffinic hydrocarbons. According to Table 3, the isolated paraffins have a higher melting point of $64{ }^{\circ} \mathrm{C}$ if the cyclohexanol consumption is $0.5 \%$ by weight. In paraffins, according to the chromatographic analysis, in this variant of the process the ratio of the number of paraffins of the normal structure to the paraffins of the isostroenie increases. The results shown in Table 4 show that the addition of cyclohexanol to the base solvent of the low temperature crystallization process makes it possible to improve the selectivity of the separation of the raffinate obtained during the extraction of the vacuum distillate VD-3 into the rape and dewaxing, since the averaged dewaxer molecule includes more aromatic oxygen-containing, naphthenic, sulfur-containing and less aliphatic structures.

Thus, an analysis of the experimental data on the selective purification of the oil distillate VD-2 with $\mathrm{N}$-methylpyrrolidone containing a cyclohexanol additive (1.5 wt.\%) And low-temperature dewaxing of the raffinate isolated from the oil distillate VD-3 in an acetone-toluene solvent containing the addition of cyclohexanol $(0.5 \mathrm{wt} . \%)$ showed that cyclohexanol as an additive to the base solvents of extraction processes makes it possible to improve the purification performance of the separation of petroleum oil fractions without substantially changing the industrial technology.

\section{REFERENCES}

[1] Ivanov, A. V. (2000). N-methylpyrrolidone instead of phenol in the purification of oil. Chemistry and technology of fuels and oils. 4: 44-45.

[2] Grushova, E. I., Yusevich, A. I. (2006). Application of additives of chemical compounds for extraction intensification, flotation, adsorption processes. BSTU. Minsk.

[3] Grushova, E. I., Kuchuk, A. V. (2003). Method of aromatic hydrocarbons extraction, BY Patent, 5496.

[4] Grushova, E. I., Karpenko, O. V., Labkovich, O. V., Al'-Razoqi, A. A. (2015). Improvement of the technology of obtaining base mineral oils and paraffins. Proceedings of BSTU. Chemistry, technology of organic substances and biotechnology. 4: 126-129.

[5] Grushova, E. I., Mikhaleva, E. V. (2008). Influence of the modifier on the oil distillates dewaxing. Proceedings of BSTU. Chemistry and technology of organic substances. 4: 61-63.

[6] Ivanova, L. V., Safiyeva, R. Z., Kamelev, V. N. (2008). IR spectrometry in the analysis of oil and petroleum products. Vestnik of Bashkir University. 4: 869-874.

AUTHORS' BIOGRAPHY

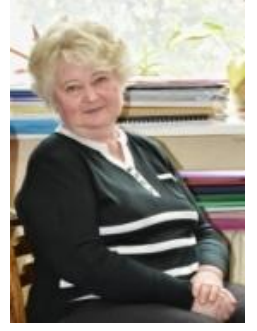

Grushova Evgeniya Ivanovna, D.Sc (Engineering), Professor, Department of Oil and Gas Processing and Petroleum Chemistry. Belarusian State Technological University (13a, Sverdlova str., 220006, Minsk, Republic of Belarus) 


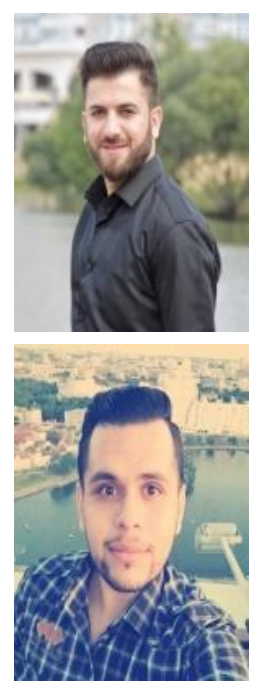

Al-Razoqi Ahmed Adnan, PhD student, Department of Oil and Gas Processing and Petroleum Chemistry. Belarusian State Technological University (13a, Sverdlova str., 220006, Minsk, Republic of Belarus).

Alrashedi Aymen Rashad, PhD student, Department of Oil and Gas Processing and Petroleum Chemistry. Belarusian State Technological University (13a, Sverdlova str., 220006, Minsk, Republic of Belarus).

Citation: Al-Razoqi A. A et al, (2017). The Effect of Cyclohexanol in Extraction Processes in the Production of Mineral Oils, International Journal of Petroleum and Petrochemical Engineering (IJPPE), 3(4), pp.78-81, DOI: http://dx.doi.org/10.20431/2454-7980.0304007

Copyright: (C) 2017 Al-Razoqi A. A. This is an open-access article distributed under the terms of the Creative Commons Attribution License, which permits unrestricted use, distribution, and reproduction in any medium, provided the original author and source are credited 